\title{
First Computed Tomography Evidence of Pulmonary Cavitated Lipoma: Diagnosis and Management
}

\author{
Tullio Valente ${ }^{1}$ Giorgio Bocchini ${ }^{1}$ Gaetano Rea ${ }^{1}$ Marianna Paccone ${ }^{1}$ Giuseppe Vitale $^{1}$ \\ Giacomo Sica ${ }^{1}$ \\ ${ }^{1}$ Section of General Radiology, Department of Diagnostic Imaging, \\ Azienda dei Colli, Monaldi Hospital, Naples, Italy \\ Address for correspondence Giacomo Sica, MD, PhD, Section of \\ General Radiology, Department of Diagnostic Imaging, Section of \\ General Radiology, Azienda Ospedali dei Colli, Monaldi Hospital, \\ Indian J Radiol Imaging 2021;31:758-760. \\ 80131 Naples, Italy (e-mail: gsica@sirm.org).
}

\begin{abstract}
Lipomas are the most common form of benign soft tissue tumors in humans, occurring infrequently in visceral organs. Pulmonary lipomas are seen rarely and can occur such as an endobronchial (80\%) or peripheral parenchymal (20\%) lesion. Less than 10 cases of lung peripheral lipoma are described in literature, none cavitated. We report the clinical case of a 51-year-old emphysematous smoker man with a peripheral intra-

\section{Keywords}

- computed tomography

- management

- positron emission tomography

- pulmonary lipoma pulmonary middle-lobe cavitating lipoma, revealed during a routine chest X-ray for emphysema, subsequently confirmed by high-resolution computed tomography (HRCT) and positron emission tomography (PET)-CT. Some hypotheses are made about the origin of cavitation. Biopsy and surgery were not done due to the fully benign nodular features at imaging. The nodule was unchanged till 2 years, last follow-up with low-dose HRCT. It is probably useful to choose a conservative approach with a followup, if there is a high suspicion of benignity.
\end{abstract}

\section{Introduction}

A lipoma is a benign mesenchymal neoplasm composed of fatty tissue. Lipomas are the most common form of benign soft tissue tumors in humans and they infrequently occur in visceral organs, such as the lungs. ${ }^{1,2}$ Pulmonary lipomas constitute approximately 0.1 to $1.3 \%$ of benign bronchial neoplasms. ${ }^{2-5}$ They can occur as an endobronchial $(80 \%)$ or as extremely uncommon (20\%) peripheral parenchymal lesion. ${ }^{2-7}$ From the literature review, less than 10 cases of lung peripheral lipoma have been reported in literature, none cavitated. ${ }^{2-9}$ We report a unique case of peripheral pulmonary cavitated lipoma in a 51year-old man which revealed during a routine chest X-ray for emphysema evaluation, confirmed by high-resolution computed tomography (HRCT) and with positron emission tomography (PET)/CT. We propose our imaging-guided management of this rare lesion.

\section{Case Report}

A 51-year-old man was referred to our Hospital Respiratory Clinic for a routine check-up due to history of emphysema. He was a 20-pack-year smoker and also affected by diabetes mellitus and hypertension. He was afebrile, normotensive, and normocardic; laboratory reports, including C-reactive protein, revealed normal blood count, and renal/liver function tests were also normal. Physical examination was significant only for sibilant wheezing rhonchus in the lungs and no other relevant abnormalities. Chest radiograph showed a nodular cavitated opacity in the right lung, close to the hilum (- Fig. 1). Chest HRCT confirmed centrilobular emphysema in the upper lung lobes and revealed a $3 \mathrm{~cm} \times 2.6 \mathrm{~cm}$ round well-circumscribed nodule in the middle lung lobe without any fissural contact, with just thickened medial wall and thin lateral margin. The lesion had fat attenuation (i.e., -130 to $-140 \mathrm{HU}$ ) and a central

(c) 2021. Indian Radiological Association. All rights reserved.

This is an open access article published by Thieme under the terms of the Creative Commons Attribution-NonDerivative-NonCommercial-License, permitting copying and reproduction so long as the original work is given appropriate credit. Contents may not be used for commercial purposes, or adapted, remixed, transformed or built upon. (https://creativecommons.org/ licenses/by-nc-nd/4.0/)

Thieme Medical and Scientific Publishers Pvt. Ltd., A-12, 2nd Floor, Sector 2, Noida-201301 UP, India 


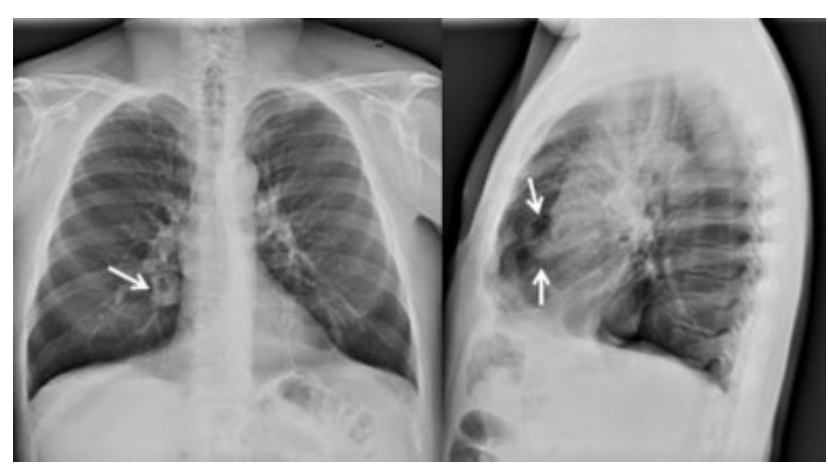

Fig. 1 Posteroanterior and lateral chest radiograph views show a well-defined rounded middle lobe cavitating nodular lesion (arrows).

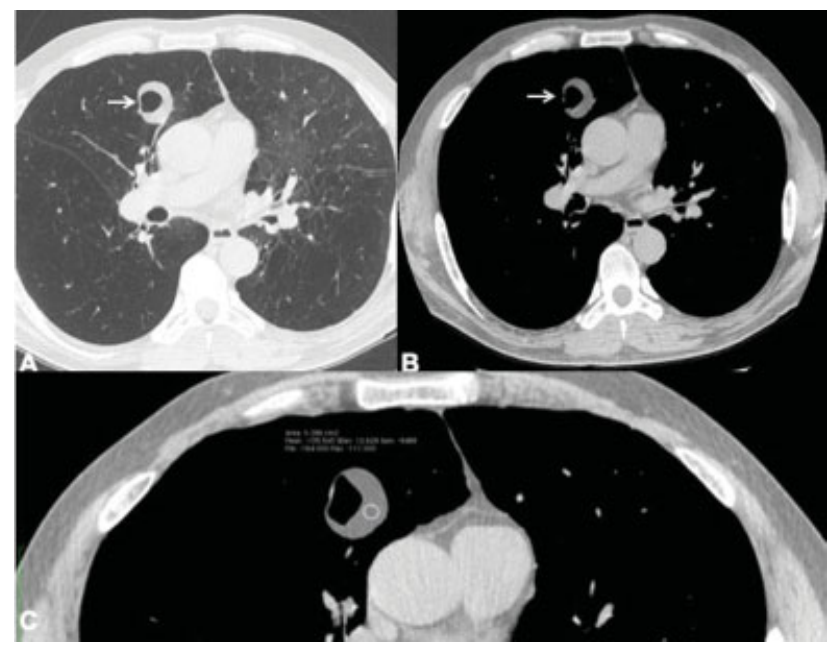

Fig. 2 High resolution CT axial images at (A) lung window and (B) mediastinal window confirm a well-defined, rounded centrally cavitated middle lobe (medial segment) lesion (arrows), measuring $3 \mathrm{~cm} \times 2.6 \mathrm{~cm}$ in the maximum transverse dimension. (C) Lung nodule attenuation values are of 120 to $140 \mathrm{UH}$, clearly indicating the presence of fat. The lesion was highly suggestive of a peripheral cavitated lung lipoma. CT, computed tomography.
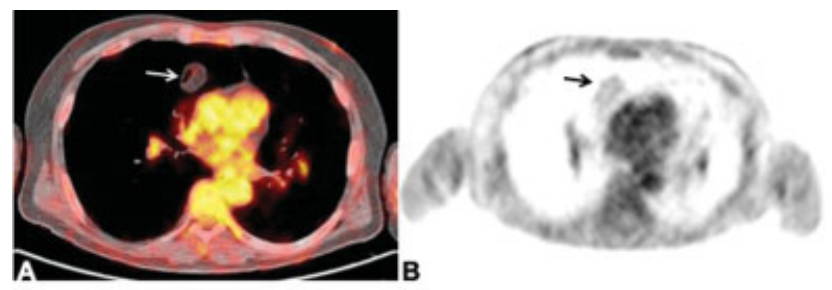

Fig. 3 A 18-F fluorodeoxyglucose positron emission tomography/computed tomography (18-F FDG PET-CT) examination shows a low grade of FDG uptake in the known middle lobe pulmonary nodule (SUV, Standardized uptake value max 1.1), confirming a benign lesion (arrows). CT, computed tomography; SUV, standardized uptake value.

inner thin-walled homogeneous air-density cavitation area, without debris and visible communication with the bronchial tree (-Fig. 2). No vessels, necrosis, air bronchogram, or calcification was present within nodule. Evaluation of the mediastinum revealed no adenopathy, and there were no features of malignancy. An 18-fluorodeoxyglucose PET/CT scan was subsequently performed and the nodule did not reveal an abnormal

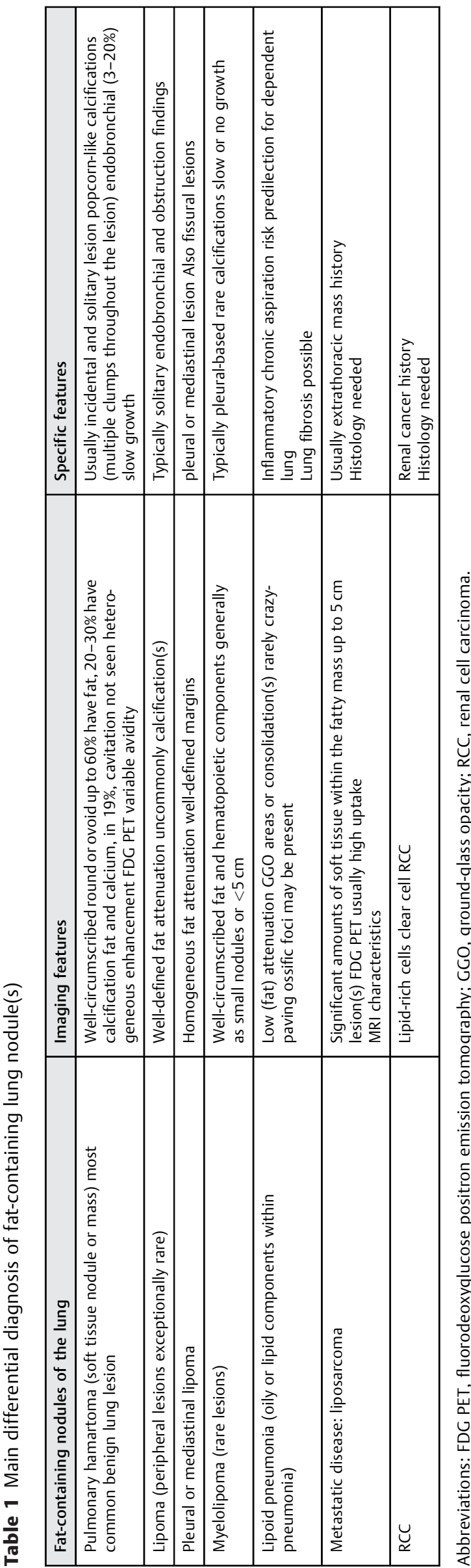


uptake ( - Fig. 3). All imaging features suggested a benign lesion, and patient received a lipoma diagnosis. He was admitted to a 6month and then annual low-dose HRCT surveillance without biopsy or surgical intervention. The nodule remains unchanged after 2 years of HRCT follow-up.

\section{Discussion}

Intrapulmonary lipomas are rare fat-containing benign lung lesions. There are different theories about their intrapulmonary origin. Endobronchial lipomas are usually surrounded by bronchial epithelium, probably arising from adipose tissue within proximal lobar or segmental bronchial wall.

The origin of peripherical lipomas can be from peribronchial or subpleural fat tissue. Clinical presentation differs according to the origin. Most peripheral lipomas are asymptomatic, with the majority being found incidentally on routine radiographs as solitary opacities, indistinguishable on plain films from malignant neoplasms. ${ }^{2-9}$ Conversely, endobronchial ones can present with atelectasis, cough, fever, and pneumonia. ${ }^{10}$ Risk factors are smoking, obesity, and diabetes mellitus. ${ }^{1}$ The main commonest entity considered in the differential diagnosis of intrapulmonary nodules containing fat is hamartoma (-Table 1). Pulmonary hamartomas frequently have focal areas of fat (up to 60\%) alternating with solid areas and typically dispersed popcorn calcifications (from 5 to 50\%). ${ }^{2,11}$ Magnetic resonance imaging (MRI) also enables the distinction of different lesion components, including fat. Fat within a lesion appears hyperintense on T1- and T2-weighted images and shows decreased signal intensity on fat-saturation techniques. Opposed phase gradient-echo MRI can show evenly distributed microscopic intralesional fat. ${ }^{12}$

The originality of the described lipoma is that it appears cavitated and features never described in the medical literature to our knowledge. A cavity is defined in the Fleischner glossary as "a gas-filled space, seen as a lucency or lowattenuation area, within pulmonary consolidation, a mass, or a nodule." ${ }^{12}$ Many types of solitary pulmonary nodules may result in cavitation, so its presence or absence is of limited diagnostic value. In our case, the absence of debris and thickening of the cavitation wall excludes a suppurative, caseous, or ischemic necrosis. Conversely, it is possible to think to a nodular encasement of a panlobular emphysema/bulla area or of a cystic dilation of microscopic bronchial structure.

\section{Conclusion}

In conclusion, both CT and MRI can help to identify intranodular fat, and PET/CT may show a normal physiological uptake; all these are reliable indicator of benign nature, excluding the use of invasive procedures, such as pulmonary biopsy or surgery. Although rare, peripheral lung cavitated lipomas should be included in the differential of fat-containing lung lesions. A suggested image-guided management option includes watchful waiting (wait and see) with followup CT imaging.

\section{Conflict of Interest}

The authors declare that they have no conflict of interests with any constitutional government, and that no pharmaceutical or medical company was involved in this report.

\section{References}

1 Plachta A, Hershey H. Lipoma of the lung. Review of the literature and report of a case. Am Rev Respir Dis 1962;86:912-916

2 Gaerte SC, Meyer CA, Winer-Muram HT, Tarver RD, Conces DJ Jr. Fat-containing lesions of the chest. Radiographics 2002;22(spec no):S61-S78

3 Zhu CM, Chang L, Ge XS, Yuan XY, Cao L. Intrapulmonary lipoma: a case report and literature review. World J Pediatr 2015;11(02): 185-187

4 Hirata T, Reshad K, Itoi K, Muro K, Akiyama J. Lipomas of the peripheral lung-a case report and review of the literature. Thorac Cardiovasc Surg 1989;37(06):385-387

5 Wood J, Henderson RG. Peripheral intrapulmonary lipoma: a rare lung neoplasm. Br J Radiol 2004;77(913):60-62

6 Erkiliç S, Koçer NE, Tunçozgür B. Peripheral intrapulmonary lipoma: a case report. Acta Chir Belg 2007;107(06):700-702

7 Castro Ramírez N, Cano Pazmiño F, Rivera Rivera T. Peripheral intrapulmonary lipoma: a case report [in Spanish]. Arch Bronconeumol 2015;51(07):360-361

8 Takahashi Y, Shima T, Harada M, Horio H. Thoracoscopic enucleation for intrapulmonary lipoma: case report. Asian Cardiovasc Thorac Ann 2015;23(03):338-340

9 Muraoka M, Oka T, Akamine S, et al. Endobronchial lipoma: review of 64 cases reported in Japan. Chest 2003;123(01):293-296

10 Siegelman SS, Khouri NF, Scott WW Jr., et al. Pulmonary hamartoma: CT findings. Radiology 1986;160(02):313-317

11 Hansell DM, Bankier AA, MacMahon H, McLoud TC, Müller NL, Remy J. Fleischner Society: glossary of terms for thoracic imaging. Radiology 2008;246(03):697-722

12 Molinari F, Bankier AA, Eisenberg RL. Fat-containing lesions in adult thoracic imaging. AJR Am J Roentgenol 2011;197(05): W795-813 